\title{
GESTATIONAL SURROGACY AGREEMENTS: WHY INDIANA SHOULD HONOR THEM AND WHAT PhysiCIANS SHOULd KNOW UNTIL THEY Do
}

\author{
Alyssa James*
}

I. INTRODUCTION 176

II. BACKGROUND 178

III. CONFUSION SURROUNDING GESTATIONAL SURROGACY ARRANGEMENTS. 181

A. Issues with Birth Certificates.................................... 181

B. Varying Outcomes Between/Within States............... 182

1. Varying Outcomes and Custody Disputes............. 182

2. Pre-Birth Parentage Orders.................................. 184

IV. CURRENT GESTATIONAL SURROGACY LAWS AND MODELS OF OTHER STATES

A. Indiana's Current Gestational Surrogacy Laws ...... 187

1. Statutory Law in Indiana. 187

2. Case Law - In re Paternity and Maternity of Infant $R$.

3. Public Policy Rationale Behind Indiana's Gestational Surrogacy Laws

a. Social mores that cause opposition to gestational surrogacy.

b. Alternative arguments to policy concerns 195

B. Florida's Recognition and Strict Regulation of Gestational Surrogacy 199

C. Illinois's Welcoming Gestational Surrogacy Laws... 200

V. BENEFITS OF ADOPTING ILLINOIS-STYLE LEGISLATION .. 203

A. Intended Parents Would Have Security in the

Outcomes of their Arrangements 203

$B$. The Intent of the Parties would be a Determining

Factor in Declaration of Parentage. 205

C. Pre-Birth Determinations of Parentage would be Predictable and Readily Available. 207

J.D. Candidate, 2013, Indiana University Robert H. McKinney School of Law; B.A., 2009, Butler University. 


\section{Surrogates will be Confident in the Outcomes of their} Arrangements 207

E. Hospitals and Physicians will be Confident in their Patient Care Decisions. 208

VI. Best Practice Suggestions for Physicians AND HOSPITALS UNTIL INDIANA REGULATES AND RECOGNIZES GESTATIONAL SURROGACY AGREEMENTS 208 VII. CONCLUSION 209

\section{INTRODUCTION}

In the United States, approximately ten percent of women of childbearing age deal with infertility ${ }^{1}$ and $7.1 \%$ of married couples are infertile. ${ }^{2}$ This struggle with infertility, along with the desire to have a child genetically linked to the parents, causes many couples to undergo significant financial and emotional stress in an attempt to have a family. Gestational surrogacy (as well as traditional surrogacy) has allowed many of these women and couples to become parents to children that they may have been unable to have. ${ }^{3}$ Traditional surrogacy is the process by which the

1 Promoting Pregnancy Wellness: Statistics, AM. Pregnancy Ass'N, http://www. americanpregnancy.org/main/statistics.html (last visited Aug. 17, 2012) (There are sixty million women of child bearing age $(15-44)$ in the United States; six million of these women deal with infertility.).

2 Kevin Yamamoto \& Shelby A.D. Moore, A Trust Analysis of Gestational Carrier's Right to Abortion, 70 FoRDHAM L. REV. 93, 99-100 (2001) (For this statistic, "a couple is defined as 'infertile' if they cannot conceive a child within one year of having frequent, unprotected intercourse. In contrast to those who are unable to conceive within one year, ninety percent of couples, both of childbearing age, who engage in intercourse without using birth control for one year will conceive." Additionally, "The number of infertile women and couples in the United States is expected to climb dramatically over the next twenty-five years.").

3 Alayna Ohs, The Power of Pregnancy: Examining Constitutional Rights in a Gestational Surrogacy Contract, 29 HASTINGS Const. L. Q. 339,339 (2002) ("While surrogacy allows numerous individuals and couples to parent children in situations that might not otherwise be 
intended father and the surrogate have a child that is genetically linked to both of them. ${ }^{4}$ Gestational surrogacy allows the intended parent(s) to have a child, through advanced reproductive technology, that is either genetically linked to themselves or a donor (the surrogate has no genetic connection to the child). ${ }^{5}$ As one woman describes, after facing years of infertility, a miscarriage, and losing all four of her quadruplets that were born prematurely, gestational surrogacy was the last hope for her and her husband to parent a biological child. ${ }^{6}$ Indiana law currently does not honor surrogacy agreements of any kind, including gestational surrogacy agreements. The Indiana legislature should reevaluate the potential policy concerns surrounding gestational surrogacy and pass legislation setting forth requirements under which gestational surrogacy agreements will be honored; however, until this occurs, Indiana physicians must educate themselves on the implications of the law in order to limit their liability when dealing with childbirths resulting from these arrangements.

Part II of this Note will discuss general background information regarding gestational surrogacy, the agreements relating to this arrangement, and the physical, emotional, and financial stresses that intended parents face when entering into these arrangements. The confusion surrounding the outcomes of gestational surrogacy agreements, including issues with birth certificates and the

possible, these developments have caused scholars and courts substantial concern. Surrogacy law is unresolved in many places.").

4 Harold S. Eskin, Surrogacy Overview, LEGALSURROGACY.COM, $\mathrm{http}: / / \mathrm{www}$. legalsurrogacy.com/surrogacy`overview.htm (last visited Aug. 24, 2012).

$5 \quad I d$. (describing that, in states that honor these agreements, the ease of drafting the legal agreements in order to honor the parties' intentions).

6 Michelle Ford, Gestational Surrogacy is not Adultery: Fighting Against Religious Opposition to Procreate, 10 BARRY L. REV. 81, 81-82 (2008) (describing the author's own heartbreaking struggles through fertility treatments and lost pregnancies, while maintaining the desire of parentage. The author and her husband underwent an eight-year rollercoaster in order to have a child that was genetically linked to them. For them, gestational surrogacy was their last and only hope for having a genetic child.). 
varying outcomes between and within states will be examined in Part III. Part IV will examine the current Indiana laws regarding gestational surrogacy, the public policy considerations that have shaped those laws, and model gestational surrogacy statutes of Florida and Illinois. Part V will evaluate the benefits of Indiana adopting an Illinois-style system of regulating and acknowledging gestational surrogacy agreements, including the security in the outcomes for intended parents and surrogates, the use of intent to determine parentage, the predictability and availability of pre-birth parentage orders, and the predictability for hospitals and physicians. Lastly, Part VI of this Note will make best practice recommendations for physicians and hospitals dealing with infants born from a gestational surrogacy arrangement under the current Indiana laws.

\section{BACKGROUND}

There are two different types of surrogacy arrangements: traditional surrogacy and gestational surrogacy. Traditional surrogacy is a surrogacy relationship in which the child is genetically linked to the surrogate. ${ }^{7}$ In a traditional surrogacy relationship, the genetic father of the child may either be the intended father or a donor of the genetic material. ${ }^{8}$ It is important to note that, in these types of surrogacy arrangements, the intended mother is never genetically related to the child. ${ }^{9}$ Contrastingly, gestational surrogacy is a surrogacy relationship in which the surrogate has no genetic link to the child. ${ }^{10}$ Most often, both of the intended parents contribute genetic material to be implanted into the surrogate. ${ }^{11}$ Gestational surrogacy arrangements may also involve a donor of the genetic

7 Denise E. Lascarides, $A$ Plea for the Enforceability of Gestational Surrogacy Contracts, 25 HofSTRA L. REV. 1221, 1225-26 (1997).

$\begin{array}{ll}8 & \text { Id. } \\ 9 & \text { Id. } \\ { }_{10} & \text { Id. at } 1226 . \\ { }_{11} & \text { Id. }\end{array}$


material of the male, female, or both. ${ }^{12}$ However, this Note will focus on gestational surrogacy arrangements in which the intended parents are also the genetic parents of the child.

The first child in the United States to be born out of a gestational surrogacy arrangement was born in $1985 .{ }^{13}$ The federal government has not established a role for itself in reproductive technology regulation; therefore, states are left to determine their views regarding gestational surrogacy and other reproductive technologies. ${ }^{14}$ States vary greatly in their interpretations and acknowledgements of gestational surrogacy agreements; in many states, surrogacy law is unresolved or ruled to be illegal altogether. ${ }^{15}$ This variance of the laws between states can make navigating reproductive technologies, especially gestational surrogacy, very challenging for intended parents, surrogates, attorneys, and physicians.

Gestational surrogacy is not an arrangement that intended parents and/or surrogates enter into lightly. It is a process that involves significant medical procedures and expense. In order to complete a successful gestational surrogacy process, the intended mother (or egg donor) must first have her eggs harvested, potentially using fertility drugs to increase egg production. ${ }^{16}$ The intended mother

12 Id.

13 Id.

14 Tenth Annual Review of Gender and Sexuality Law: Health Care Law Chapter: Assisted Reproductive Technologies, 10 GEO. J. GENDER \& L. 859, 859-60 (James W. Ringo ed. 2009); see also Lascarides, supra note 7 , at 1227 ("Since Congress has yet to enact federal legislation relating to such contracts, the issue has not been resolved consistently by the state courts and state legislatures.").

15 Ohs, supra note 3 , at 339-40; Lascarides, supra note 7 , at 1227 ("[C]ertain states may become havens for infertile couples seeking children through traditional or gestational surrogacy. Uniform regulation is needed so that infertile couples in every state are offered the same opportunity to produce a genetic offspring through surrogacy arrangements.").

16 The Gestational Surrogacy Process: An Overview of a Typical IVF Cycle, ALLABOUTSURROGACY.COM, http://www.allaboutsurrogacy. com/gsprocess.htm (last visited Aug. 3, 2012) (asserting that by 
and the surrogate must also synchronize their menstrual cycles, which requires multiple injections and medications; finally, the eggs are retrieved from the intended mother. ${ }^{17}$ The eggs are then incubated in a laboratory until the father (or donor) produces a sperm sample to inseminate the eggs in a laboratory dish via in vitro fertilization (forming embryos).18 These embryos are then transferred into the surrogate's uterus and a pregnancy test is performed two weeks later to determine whether or not the procedure was successful. ${ }^{19}$

Intended parents often prefer gestational surrogacy because they desire a genetic child. ${ }^{20}$ Parents often have the assumption that a child that is genetically linked to them will be more likely to be awarded to them in the event of a custody dispute with the surrogate. ${ }^{21}$ As will be evaluated in this Note, this is not always the case; however, gestational surrogacy arrangements are typically more promising for intended parents than traditional surrogacy arrangements. In the event of a custody dispute between the intended parents and the surrogate, a surrogate with no genetic ties to the child has a much lower chance of being awarded custody of the child. ${ }^{22}$

increasing the number of eggs removed from the intended mother, the number of potential embryos will also increase, thus further increasing the likelihood of pregnancy).

17 Id.

$18 I d$.

19 Id. ("The embryo transfer may be done 3-5 days after the retrieval. The physician performing the transfer will discuss with the carrier and the intended parents the status of the embryos and the number to be replaced. The number of embryos transferred varies according to their quantity and quality. At this point, there may be an opportunity to cryopreserve any remaining embryos that continue to develop normally, for possible transfer in future cycles." If the pregnancy test is positive, the surrogate will typically maintain visits to the fertility doctor for several weeks before visiting the obstetrician of her choice.).

20 Amy M. Larkey, Redefining Motherhood: Determining Legal Maternity in Gestational Surrogacy Arrangements, 51 DRAKE L. REV. 605,611 (2003).

21 Id.

22 See generally id. (stating that "the absence of a genetic link 


\section{Confusion SurRounding GESTATIONAL SuRROGacy ARRANGEMENTS}

\section{A. Issues with Birth Certificates}

Traditionally, there was no legal definition of the word 'mother' because there was no other way for someone to become a mother other than giving birth to a child. ${ }^{23}$ Because there is no legal interpretation of the word 'mother,' much controversy arises when a court must determine the legal mother of a child born via gestational surrogacy. ${ }^{24}$ In Indiana, as in many other states, the gestational surrogate/birth mother's name is most often placed on the birth certificate and the intended mother later must petition the court for the mother's name to be changed to her name. ${ }^{25}$ Very rarely do gestational surrogates want their name to be listed on the child's birth certificate at all; they would rather have the intended parents assume all responsibility of the child upon birth. ${ }^{26}$ Some states have ruled that forcing the birth mother to place her name on the

between the surrogate and child arguably creates a stronger legal position for the biological parents in the event of a legal custody battle").

23 Erin Y. Hisano, Gestational Surrogacy Maternity Disputes: Refocusing on the Child, 15 LEWIS \& CLARK L. REV. 517, 519 (2011).

24 Id. For example, in the case of Scott and Amy Kehoe, who enlisted a gestational surrogate to have their child, the surrogate was ruled by the court to be the legal mother of the twins she birthed for the Kehoes. Id. In this instance, the Kehoes used the reproductive material from a male and female donor, meaning they were not the genetic parents of the twins; however, the gestational surrogate was also not genetically related to the children. Id. In this case, the gestational surrogate decided to assert her right under Michigan law to keep the twins when she learned that Amy Kehoe "had a history of mental illness and a minor criminal record." Id. The Kehoes chose "not to pursue any further legal action." Id.

25 Michele L. Jackson \& Lynn Mullins-Owens, Assisted Reproductive Technology Indiana: The Latest Legal News on Surrogacy, Artificial Insemination, and Donor Arrangements (Jocham Harden Dimick \& Jackson, PC, Carmel, Ind.), Spring 2011, at 3.

26 See Tenth Annual Review, supra note 14, at 877-78; Ashley E. Bashur, Whose Baby is it Anyway? The Current and Future Status of Surrogacy Contracts in Maryland, 38 U. BALT. L. REV. 165, 178-79 (2008). 
certificate when she does not desire to do so violates the Equal Rights Amendment because it prevents "women from denying maternity while allowing men to deny paternity." 27 Because men cannot be forced to have their name listed on a child's birth certificate without the chance to prove their lack of paternity, women should be afforded this same right. ${ }^{28}$ Because our society is used to correlating birth mothers with maternity, this right is not always afforded to gestational surrogates without a petition to the court. ${ }^{29}$

\section{B. Varying Outcomes Between/Within States}

\section{Varying Outcomes and Custody Disputes}

The primary source of confusion amongst parties interested in gestational surrogacy is the variance of surrogacy laws amongst states. Often, it can be difficult to predict how a court will rule when issues with a gestational surrogacy arrangement arise. In Indiana, it can be especially difficult to predict outcomes because gestational surrogacy agreements are unenforceable; however, Indiana does not forbid surrogacy itself. ${ }^{30}$ Indiana forbids honoring gestational surrogacy agreements because the legislature deems them to be contrary to public policy. ${ }^{31}$ Indiana attorneys are able to draft agreements as best as they can; however, there is no guarantee as to the result of the situation. ${ }^{32}$ Outcomes of gestational surrogacy arrangements can be unpredictable in other states as well.

27 Tenth Annual Review, supra note 14, at 878.

28 Erin V. Podolny, Are You My Mother?: Removing a Gestational Surrogate's Name From the Birth Certificate in the Name of Equal Protection, 8 U. MD. L. J. RACE, RELIGION, GENDER \& Class 351, 351 (2008) (stating that in the case of In re Roberto d.B., the court ordered that the surrogate's name be removed from the birth certificate and a new certificate be reissued solely in the name of the father).

$29 \quad I d$. at 365.

30 Gestational Surrogacy Program, FAMILY BEgINNINGS, http:// www.ivfindiana.com/gestational-surrogacy-program.html (last visited Aug. 3, 2012).

31 IND. CODE $\S 31-20-1 \cdot 1$ (2012).

32 Gestational Surrogacy Program, supra note 30, at 1. 
In A.G.R. V. D.R.H. \& S.H., the Superior Court of New Jersey declared the gestational surrogate to be the legal mother of a set of twins that she carried for her brother and his partner. ${ }^{33}$ In that case, the intended parents (a homosexual couple that had a registered civil union in New Jersey and had been legally married in California) entered into a gestational surrogacy agreement with the sister of one of the men. ${ }^{34}$ The sperm of one of the partners and a donor egg were used; the gestational surrogate was not genetically related to the child. ${ }^{35}$ This ruling provided the gestational surrogate with the "right to seek primary custody of the children." 36

Contrastingly, in Maryland, as long as both the intended parents and the gestational surrogate are in agreement, the court will honor the gestational surrogacy agreement. ${ }^{37}$ However, if the surrogate desires to attempt to establish parental rights, Maryland has not necessarily established an 'intent' test to determine parentage, which can be very troublesome for intended parents. ${ }^{38}$ These varying laws amongst states create a confusing atmosphere for parents desiring to have a child via gestational surrogacy. The best hope for parents is to consult with attorneys and thoroughly research the surrogacy laws of their state in order to attempt to create the best possible scenario for a positive

33 A.G.R. v. D.R.H., No. FD-09-001838-07 (N.J. Super. Ct. Ch. Div. Dec. 23, 2009), available at http://www.nytimes.com/packages/pdf/ national/20091231_SURROGATE.pdf.

$34 \quad I d$. at 2.

35 Id.

36 Stephanie Saul, New Jersey Judge Calls Surrogate Legal Mother of Twins, N.Y. TIMES, Dec. 30, 2009, http://www. nytimes.com/2009/12/31/us/31surrogate.html?_r=1. In this case, the judge equated the Baby $M$ decision with that of his own; eluding to the fact that intended parents have no more merit to their claims for parentage regarding children born to a gestational surrogate than they do for children born to a traditional surrogate. Id. If upheld, this decision will drastically change the traditional view that intended parents are more protected in their parenthood status when they are genetically linked to the child. $I d$.

37 Bashur, supra note 26, at 182.

$38 \quad I d$. at 183. 
outcome of the arrangement. ${ }^{39}$

Additionally, states that do not honor gestational surrogacy agreements often vary from case to case as to how they deal with gestational surrogacy arrangements. For example, some states treat surrogacy arrangements like adoptions, giving the surrogate a period of time (typically seventy-two hours) after the child is born to decide whether or not she wants to keep the child. ${ }^{40}$ Though it is very uncommon for a gestational surrogate to attempt to keep the child, the possibility of a court battle dissuades many intended parents from pursuing a gestational surrogacy arrangement. ${ }^{41}$

\section{Pre-Birth Parentage Orders}

In some states, courts will issue a pre-birth order that establishes the intended parents as the parents whose names should be placed on the child's birth certificate. ${ }^{42}$ For example, New Hampshire provides for a pre-birth determination of parentage "which results in the automatic termination of the surrogate's parental rights after 72 hours following delivery; this allows the intended parents' names to be entered on the child's original birth certificate and there is never a reference to the gestational surrogate's

39 The Law, THE SURROGACY EXPERIENCE, http://www. thesurrogacyexperience.com/surrogates.cfm?sc $=23 \& \mathrm{p}=97$ (last visited Aug. 3, 2012).

40 Browne C. Lewis, Three Lies and a Truth: Adjudicating Maternity in Surrogacy Disputes, 49 U. LOUISVILLE L. REV. 371, 380 (2011).

41 Heléna Ragoné, Surrogacy-Cultural/Legal Implications, JRANK.ORG, http://family.jrank.org/pages/1666/Surrogacy-CulturalLegal-Implications.html (last visited Aug. 3, 2012).

42 The Pre-Birth Parentage Order, The SurRogacy EXPERIEnce, http://www.thesurrogacyexperience.com/surrogates. $\mathrm{cfm}$ ?sc $=23 \& \mathrm{p}=100$ (last visited Aug. 3, 2012); U.S. Surrogacy Law by State, THE SURROGACY EXPERIENCE, http://www.thesurrogacyexperience.com/ surrogates.cfm?sc $=23 \& p=99$ (last visited Aug. 3, 2012) (stating that Connecticut, Indiana, New Jersey, Ohio, and Pennsylvania are some of the states whose judges will grant pre-birth orders (although usually on an inconsistent basis)). 
name."43 Due to the lack of statutory guidance in many states, it can be difficult to predict whether or not a particular court will grant or deny a pre-birth parentage order. ${ }^{44}$ The issuance of pre-birth parentage orders can vary state-by-state, "county by county and even on a judge by judge basis." 45 However, the correlation some courts make between gestational surrogacy and adoption causes those courts to not issue pre-birth orders due to the mandatory waiting period associated with adoptions. ${ }^{46}$ Although some pre-birth orders may still be granted, there is not much assurance for the intended parents regarding the outcome of such proceedings until the hearing for the pre-birth order occurs. ${ }^{47}$ In Indiana, pre-birth orders may be granted inconsistently due to the state's refusal to acknowledge gestational surrogacy agreements, ${ }^{48}$ which may cause a tumultuous situation for both the intended parents and the gestational surrogate. ${ }^{49}$ The reason for this inconsistency is that "Indiana currently has no laws that specifically allow or prohibit pre-birth parentage orders." 0

In Belsito v. Clark, an Ohio court determined that the intended parents should be acknowledged as the legal and natural parents of an unborn child being carried by a surrogate. ${ }^{51} \mathrm{In}$ this case, Mr. and Mrs. Belsito desired to have a child, but Mrs. Belsito had had a hysterectomy and was unable to conceive; therefore, her sister became the gestational surrogate for the couple. ${ }^{52}$ Prior to the birth of

43 Ford, supra note 6, at 90.

44 U.S. Surrogacy Law by State, supra note 42.

45 Id. ("In every case where surrogacy is permitted but there is neither a statute nor a ruling from the state's highest court governing the process, the question of pre-birth orders will be determined on a county by county and even on a judge by judge basis. This greatly complicates the issuance of birth certificates in the name(s) of the intended parent(s) and not the name of the surrogate and, if she is married, her husband.").

46 Larkey, supra note 20 , at 611.

47 Id.

48 U.S. Surrogacy Law by State, supra note 42.

49 Jackson, supra note 25 , at 3.

$50 \quad I d$.

51 Belsito v. Clark, 644 N.E.2d 760, 768 (Ohio Com. Pleas 1994).

52

Id. at 761 . 
the child, Mrs. Belsito contacted the hospital and was told that the surrogate's name would be placed on the birth certificate and that, because the surrogate and Mr. Belsito were not married, the child would be considered illegitimate and listed as "Baby Boy Clark' and not as 'Baby Boy Belsito." 53 As an issue of first impression, the Ohio court entered into a lengthy discussion and eventually determined that biology should determine that the Belsitos be considered the legal and natural parents of the child. ${ }^{54}$ Because there was no statutory law regarding gestational surrogacy in Ohio, the court's decision was unpredictable by the parties in this scenario. ${ }^{55}$ Although this outcome was good news for the Belsitos, it was unclear if the court would have reached the same decision if donor genetic material had been used during the IVF process.

The Ohio courts answered this question in the case of $S . N$. V. M.B.56 In this case, the intended mother and her fiancée used a gestational surrogate to carry a child that was created using male and female donor material, meaning that neither of the intended parents or the surrogate would have a genetic link to the child. 57 The gestational surrogate became pregnant with twins; however, the twins were born premature and one of them did not survive. 58 While the determination of maternity was being decided by the courts, the surviving twin was released from the hospital to the surrogate; the surrogate then relinquished day-to-day care to a third party. ${ }^{59}$ The gestational surrogate refused to comply with the written surrogacy agree-ment and filed a

$53 \quad I d$. at 762.

54 Id. at 768.

55 Victoria L. Fergus, An Interpretation of Ohio Law on Maternal Status in Gestational Surrogacy Disputes: Belsito v. Clark, 644 N.E.2d 760 (Ohio C.P. Summit County 1994), 21 DAYTON L. REV. 229, 234 (1995) (explaining that the court denied the use of the intent test because it did not acknowledge public policy issues and failed "to recognize the genetic mother's rights.").

56 S.N. v. M.B., 935 N.E.2d 463 (Ohio App. 2010).

57 Id. at $464-65$.

58 Id. at 465.

$59 \quad I d$. 
claim for custody of the child. ${ }^{60}$ After a long and tumultuous court battle, the Court of Appeals of Ohio, recognizing the validity of the gestational surrogacy agreement, granted custody to the intended parents. ${ }^{61}$ In this case, the intended parents' child was over two years old by the time the courts determined parentage and resolved custody. ${ }^{62}$ Although this was, in the end, a favorable outcome for the intended parents, the court's reliance on the validity of the gestational surrogacy agreement ${ }^{63}$ is unsettling for intended parents in Indiana, where such agreements are not recognized. ${ }^{64}$

\section{Current Gestational SuRrogacy LaWs and Models OF OTHER STATES}

\section{A. Indiana’s Current Gestational Surrogacy Laws}

\section{Statutory Law in Indiana}

In Indiana, all surrogacy agreements entered into after 1988 are void.65 This is due to the Indiana legislature's determination that enforcement of surrogacy agreements is against public policy.66 The Indiana legislature has determined that surrogacy agreements containing the following provisions are against public policy:

(1) Provide a gamete to conceive a child. (2) Become pregnant. (3) Consent to undergo or undergo an abortion. (4) Undergo medical or psychological treatment or examination. (5) Use a substance or engage in activity only in accordance with the demands of another

60 Id.

61 Id. at $472-73$.

62 Id. (The child was born on May 15, 2008; however, the Court of Appeals of Ohio did not issue its opinion until June 10, 2010.).

63 Id. at 470-73.

64 IND. CODE $\S 31-20-1-2$ (2012).

65 Id.

66 IND. CODE $\S 31-20-1-1$ (2012). 
person. (6) Waive parental rights or duties to a child. (7) Terminate care, custody, or control of a child. (8) Consent to a stepparent adoption under IC $31-19$ (or IC $31-3-1$ before its repeal). 67

This statute makes clear the legislature's intent to prevent the recognition of both traditional and gestational surrogacy agreements. Many states that render gestational surrogacy agreements void do so because of the belief that "birth mothers are contracting away their parental rights."68 However, there are remedies for this perception: "a gestational carrier should never be presumed to have any parental rights, as the implanted embryo is not genetically related to her." 69

As a result of the nullification of surrogacy agreements, it can be difficult to predict the outcomes of gestational surrogacy arrangements in Indiana. Indiana defines a surrogate agreement as an:

agreement that is entered into before the birth of a child ... that is intended by the parties at the time that the agreement is made to induce the surrogate to relinquish care, custody, and control over the child at birth to any of the following: (1) An intended biological parent of the child ... (3) Two (2) intended biological parents of the child. ${ }^{70}$

Additionally, Indiana defines a surrogate as a person who:

bears a child that is genetically related to: (1) the party who agrees to bear or bears the child

67 Id.

68 Ford, supra note 6, at 90 (explaining that in addition to the example of Indiana's finding that gestational surrogacy agreements are void, Michigan, New York, and other states have also created laws stating the same.).

69 Id.

70 IND. CODE $§ 31-9-2-127$ (2012). 
and an intended biological parent; (2) an intended biological parent and a gamete donor who is not: (A) an intended biological parent; and (B) the spouse of the party who agrees to bear or bears the child; or (3) two (2) intended biological parents of the child. ${ }^{71}$

The plain language of these statutes indicates that the Indiana legislature has a strong distaste for all forms of surrogacy, including gestational surrogacy. Further, Indiana courts cannot make custody decisions, or "best interest of the child" decisions, based solely on the existence of a surrogacy agreement. ${ }^{72}$ Therefore, the Indiana statutory scheme provides little security for individuals entering into surrogacy arrangements because, in the event a discrepancy arises, the intent of the parties in creating the agreement will not be used as significant evidence in favor of the gestational surrogate.

Pre-birth parentage orders may provide some sense of security; however, Indiana jurisdictions differ on whether or not they will allow parentage orders because Indiana has no specific laws that allow or prohibit them. ${ }^{73}$ The granting of pre-birth parentage orders allows the legal rights regarding the child to "vest immediately upon the child's birth."74 "There is an advantage to pre-birth establishment of parenthood, especially in dealing with control of the child immediately after the birth, removing the child from the hospital, [and] insuring the child."75 These advantages make it well worth the intended parents' efforts to try to obtain the pre-birth determination of parentage because it will allow them to take their child(ren) home from the

71 IND. CODE $\S 31-9-2-126$ (2012).

72 IND. CODE $\S 31-20-1-3$ (2012).

73 Jackson, supra note 25 , at 3.

74 Ford, supra note 6, at 88.

75 Id. (quoting H. Joseph Gitlin, Surrogacy: Illinois Becomes Surrogacy Friendly, GITLIN, BUSCHE \& STETLER, http://www. gitlin.com/pages/IllinoisBecomesSurrogacyFriendly. html (last visited Aug. 3, 2012)). 
hospital, as well as immediately be able to make medical decisions for their child(ren). ${ }^{76}$

\section{Case Law - In re Paternity and Maternity of Infant $R$.}

Indiana's leading case law regarding the interpretation of gestational surrogacy arrangements is In re Paternity and Maternity of Infant $R .77$ In that case, the gestational surrogate, who is the intended mother's sister, and the intended parents entered into a surrogacy agreement. ${ }^{78}$ All parties involved remained in agreement regarding the desired and intended parents of Infant R. ${ }^{79}$ During the pregnancy, the parties petitioned the court to establish the intended parents as the legal parents of the child. ${ }^{80}$ Despite their agreements throughout the gestational surrogate's pregnancy, the juvenile court denied the petition to establish maternity stating, "The Court finds that Indiana law does not permit a non birth mother to establish maternity. Indiana law holds the birth mother is the legal maternal mother. The Court finds and recommends that the Agreed Petition to Establish Paternity and Maternity be denied." 81

Ultimately, the Indiana Court of Appeals reversed and remanded the case to determine the biologic maternity of Infant R. to establish legal maternity of the child. ${ }^{82}$ The Indiana Court of Appeals called for action by the legislature, noting that:

no legislation enacted in this State specifically provides procedurally for the establishment of maternity; it is presumed that a woman who

76 Ford, supra note 6, at 88 .

77 In re Paternity and Maternity of Infant R., 922 N.E.2d 59 (Ind. Ct. App. 2010).

$\begin{array}{ll}78 & I d . \text { at } 60 . \\ 79 & I d . \\ 80 & I d . \\ 81 & I d . \\ 82 & I d \text {. at } 62 .\end{array}$


gives birth to a child is the child's biological mother . . . we are confronted with reproductive technologies not contemplated when our Legislature initially sought to provide for the establishment of legal parentage for biological parents . . . it is for the legislature to evaluate and deliberate comprehensive proposals for changes to these statutes. ${ }^{83}$

In re Paternity and Maternity of Infant $R$. shows just how complicated the gestational surrogacy/establishment of maternity process can be. The involved parties in that case originally filed to establish paternity and maternity in December 2008.84 Maternity was not established until after this decision was issued in February 2010 (after Infant R. was over one year old). ${ }^{85}$ In situations of contested custody, this one-year lapse in determination of maternity could be very detrimental to all parties involved. Even in noncontested situations, a one-year lapse in the determination of parentage can take valuable time away from the intended parents and their child(ren).

3. Public Policy Rationale Behind Indiana's Gestational Surrogacy Laws

a. Social mores that cause opposition to gestational surrogacy

Many argue that gestational surrogates "challenge our most basic ideas about motherhood, and call into question what we've always thought of as an unbreakable bond between mother and child." 86 It is this challenge to

$83 \quad I d$. at 61.

$84 I d$. at 60.

$85 \quad I d$. at 62.

86 Lorraine Ali, The Curious Lives of Surrogates, DAILY BEAST (Mar. 29, 2008, 10:55 AM),http://www.thedailybeast.com/newsweek/ 2008/03/29/the-curious-lives-of-surrogates.html (describing the intricate 
traditional notions of motherhood and additional social stigmas surrounding surrogacies that cause many to look unfavorably upon gestational surrogacy agreements and those who participate in them. ${ }^{87}$

Many feminists and others who oppose the legitimacy of gestational surrogacy agreements feel that these arrangements may exploit women. ${ }^{88}$ In reality, gestational surrogates are not typically as wealthy as the intended parents; however, they also are rarely poor - many are women who embrace a potential income while being able to stay home with their own children instead of working. ${ }^{89}$ Another argument against upholding gestational surrogacy agreements "is the potential problem that a child may have because he or she does not know his or her biological mother, which can be crucial to predicting cancer, heart disease, and other medical conditions."90 Although this argument is only valid for gestational surrogacy arrangements using donor genetic material, it does not hold much weight because this argument could also be made

social stigmas associated with gestational surrogates and the rigorous process they go through to bear someone else's children).

87 Id. (The author describes that the social stigma associated with gestational surrogates has even expanded into pop culture, with movies like "Baby Mama," in which "a single businesswoman (Tina Fey) is told by a doctor she is infertile. She hires a working-class gal (Amy Poehler) to be her surrogate. The client is a savvy, smart and well-to-do healthstore-chain exec while Poehler is an unemployed, deceitful wild child who wants easy money. . . . 'I just don't understand how they can think that,' says surrogate Gina Scanlon of the stereotypes that influenced the film.").

88 Elizabeth S. Scott, Show Me the Money: Making Market in Forbidden Exchange: Surrogacy and the Politics of Commodification, 72 L. \& CONTEMP. PROB. 109, 138 (2009).

89 Id. at 138-39 ("Contrary to the claim that surrogacy degrades motherhood and pregnancy, the available evidence suggests that surrogates view themselves as performing a service of great social value for the benefit of others."); Ali, supra note 86 (stating that many gestational surrogates are military wives who value their ability to help others start families, while staying home with their own children, while their husbands are on deployment).

90 Bashur, supra note 26 , at 188. 
against adoption, ${ }^{91}$ which all fifty states regulate and acknowledge..$^{92}$

Religious opposition to gestational surrogacy has also been a primary hindrance in the development of pro- $^{-}$ surrogacy legislation. ${ }^{93}$ The Catholic Church, in its Ethical and Religious Directives, has stated, "Reproductive technologies that substitute for the marriage act are not consistent with human dignity. Just as the marriage act is joined naturally to procreation, so procreation is joined naturally to the marriage act." 94 Some religious parties have equated the act of surrogacy with adultery. ${ }^{95}$ However, this argument is ill-informed because" $[t]$ he genetic material of the third-party surrogate does not intermingle with the genetics of the intended; therefore, gestational surrogacy should not be equated to adultery." 96

In a post-Baby $M$ society, some societal members are generally skeptical of surrogacy arrangements and feel that they should be prohibited to curb similar conflicts. ${ }^{97}$ Many

\footnotetext{
91 Matthew Tieu, Oh Baby Baby: The Problem of Surrogacy, BIOETHICS RES. NOTES (March 2007), http://www.bioethics.org.au/Resources/Online\%20Articles/Opinion\%20 Pieces/1901\%200h\%20Baby\%20Baby\%20The\%20Problem\%20with\%20 Surrogacy\%20MT.pdf.
}

92 See Child Adoption Laws, ChILdADOPTIONLAWS.COM, http://childadoptionlaws.com (last visited Aug. 3, 2012) (listing the relevant state adoption statutes for all fifty states).

93 See generally Ford, supra note 6, at 97-98 (describing the religious objections vocalized against surrogacy, including the belief that "[ $t$ ]he use of third-party genetic material violates the sanctity of the marriage covenant").

94 United States Conference of CATHolic Bishops, ETHICAL and Religious Directives for Catholic Health Care Services 24 (5th ed. 2009), available at http://www.ncbcenter.org/document.doc? id $=147$.

95 Ford, supra note 6, at 97-98.

$96 \quad$ Id. at 98.

97 Yamamoto, supra note 2, at 109-11 (The Baby $M$ case is an infamous case of a traditional surrogate that decided she wanted to keep the baby she had been carrying for the intended parents. Because the surrogate was also the genetic mother, it made the determination of motherhood much more complicated.); See In Re Baby M, 537 A.2d 1227 (N.J. 1988) (Baby $M$ is considered to be one of the most infamous and controversial surrogacy cases; however, it should be noted that it 
fertility clinics and gestational surrogate placement agencies now force intended parents and surrogates to submit to intense physical and psychological screening in order to reduce the risk that a surrogate will become overly attached to the baby during the surrogacy. ${ }^{98}$ Gestational surrogates are evaluated to determine their ability to not grow overly attached to the child that they will potentially carry; intended parents are also evaluated to determine their intentions will remain intact through-out the process. This is to help ensure that there will be no issues taken to court, as it is unclear how many courts will rule should a dispute arise.

Contrary to the presumption that many surrogates will feel an unexpected bond with the child they are carrying and seek parentage, most surrogates explain their relationship with the gestating child as an intense, caring babysitting role. ${ }^{99}$ Additionally, surrogates attempt to fight the stigma by justifying their actions via the response, "Tell them what that man, woman, or couple went through for years before you stepped in to take their pain away and give them a reason to live."100 Many gestational surrogates, or 'carriers' as they often refer to themselves, feel a deep sense of social satisfaction because they are able to perform "a service of great social value for the benefit of others."101 Some women also describe the sensation of enjoying being

involved a traditional surrogate, not a gestational surrogate, and thus presents very different issues and ideals than those presented in this Note.).

98 Yamamoto, supra note 2, at 123-24 Ali, supra note 86 (Gestational surrogates are evaluated to determine their ability to not grow overly attached to the child that they will potentially carry; intended parents are also evaluated to determine their intentions will remain intact throughout the process. This is to help ensure that there will be no issues taken to court, as it is unclear how many courts will rule should a dispute arise.).

99 Scott, supra note 88, at 139.

100 Ford, supra note 6, at 84.

101 Scott, supra note 88, at 139-40 (citing Janice C. Ciccarreli \& Linda J. Beckman, Navigating Rough Waters: An Overview of Psychological Aspects of Surrogacy, 61 J. SoC. IsSUES 21 (2005); Carol Sanger, Developing Markets in Baby-Making: In the Matter of Baby M, 30 Harv. J. L. \& Gender 67 (2007)). 
pregnant, while not having the desire to have more children of their own. ${ }^{102}$ Gestational surrogacy is becoming more popular, in part due to a "greater acceptance of the practice" and in part due to significant increases in success rates of fertility clinics practicing IVF. ${ }^{103}$

The passage of time since the decision of the Baby $M$ case has shown that moral panic dissipates over time making the present, rather than the period immediately following the Baby $M$ decision, a much more appropriate time for the Indiana legislature to address gestational surrogacy arrangements. ${ }^{104}$ It is time for the Indiana Legislature, as well as the legislatures of all states that deem gestational surrogacy agreements void, to reevaluate the validity of gestational surrogacy agreements.

\section{b. Alternative arguments to policy concerns}

State legislatures often ban gestational surrogacy agreements, or choose to not recognize them, because the legislatures have acknowledged a public policy concern against the "sale" of infants. ${ }^{105}$ However, gestational surrogacy agreements can be honored, and still uphold public policy, by being worded not to allow for the "sale" of

102 Ali, supra note 86 (For example, "Jennifer Cantor, a 34-year-old surgical nurse.. . loves being pregnant. Not having children, necessarily - she has one ... and has no plans for another-but just the experience of growing a human being beneath her heart.").

103 Id. (For example, the Genetics \& IVF Institute in Virginia, the clinic studies for Ali's article, advertises a success rate of $70 \%-90 \%$ for gestational surrogacy arrangements result-ing in successful pregnancies. This statistic shows a $40 \%$ increase in the past ten years.).

104 Scott, supra note 88, at 145-46 ("The passage of time allows the political climate to cool, but it can also serve another useful purpose. An extensive period dedicated to acquiring accurate information and to deliberation provides the opportunity to correct distortions created by availability cascades.").

105 Sara K. Alexander, Who is Georgia's Mother? Gestational Surrogacy: A Formulation for Georgia's Legislature, 38 GA. L. REV. 395, 415-16 (2003) (asserting that "baby-selling" has been deemed "the most controversial aspect of surrogate mother agreements"). 
an infant.106 Professor Richard Epstein "notes the term 'commodity' is misused in the surrogacy context . . . In surrogacy arrangements . . . the subjective value of the human involved precludes any useful comparison to a commodity . . . surrogacy contracts are not for resale, they are for a one-of-a-kind creation." 107 In states where gestational surrogacy is allowed, the legislature and courts have viewed the surrogates as "providers of a 'service,' rather than baby-sellers."108

Many who critique gestational surrogacy arrangements do so on the grounds that "birth mothers are contracting away their parental rights." 109 However, others argue that:

\begin{abstract}
a gestational carrier should never be presumed to have any parental rights, as the implanted embryo is not genetically related to her. This statement is not intended to trivialize the emotional bond formed between a woman and the unborn child she carries, but rather to convey the more significant relation-ship between the genetic parent and the resultant child which the contracting parties intended. ${ }^{110}$
\end{abstract}

Additionally, because maternity in gestational surrogacy situations should be decided based upon the surrogate's lack

$106 I d$. at $417-19$ (stating that gestational surrogacy agreements can reduce the implications of "selling infants" by only compensating the surrogate for medical expenses, denying pre-birth determinations of parentage, and/or "making the surrogate a 'trustee' of sorts of parental rights").

107 Kevin Tuininga, The Ethics of Surrogacy Contracts and Nebraska's Surrogacy Law, 41 CREIGHTON L. REV. 185, 194 (2008) ("[T] than bare assertions that surrogacy involves the purchasing of women and children.").

108 Ohs, supra note 3 , at 340 (asserting that viewing gestational surrogates as service providers can create issues when there are differing opinions between the intended parents and the surrogate regarding medical decisions and how she can/should treat/care for her body).

109 Ford, supra note 6, at 90.

110 Id. 
of "biological ties," the "gestational surrogate does not have the requisite standing to argue that she is the legal mother."111 This view of the rights and intentions of the parties may seem crude at first; however, it supports the rationale that gestational surrogates are simply providing a service to the intended parents, not 'selling' their own child, and therefore surrogates should not be entitled to parental rights.

Additionally, the legislature's careful drafting can minimize policy concerns regarding the potential exploitation of poor women. "The Supreme Court of California . . . has expressed the view that no hard evidence has shown poor women are exploited in surrogacy contracts in a manner distinguishable from how economic need generally induces needy individuals to accept what some would consider undesirable employment."112 For example, by not allowing additional compensation to be paid to the surrogate, states can reduce many of the risks associated with the exploitation of poor women in gestational surrogacy arrangements. ${ }^{113}$ The states of Washington, Maryland, Nebraska, and Florida are just a few of the states that recognize uncompensated surrogacy agreements but not compensated surrogacy agreements. ${ }^{114}$ Additionally, it is assumed that most intended parents "would hesitate to choose a surrogate mother in such an unstable situation if at all possible." 115 Many examples of gestational surrogates, including "a single mom . . . a military spouse . . . and a small-business owner," often defy the stereotypes of the 'type' of woman that becomes a surrogate. ${ }^{116}$ Motives for women who choose to become gestational surrogates may also defy pre-conceived notions and perceptions. For example, some women choose to be surrogates to help close friends or family members give birth to a genetic child; whereas, some choose to do so to raise extra capital for

111 Bashur, supra note 26, at 197.

112 Tuininga, supra note 107 , at 197.

113 Ford, supra note 6, at 99.

114 U.S. Surrogacy Law by State, supra note 42.

115 Tuininga, supra note 107, at 195.

116 Ali, supra note 86. 
extravagant family trips or other items which were previously out of reach financially for their families. ${ }^{117}$

Some states, such as Illinois, allow for compensation of the surrogate. ${ }^{118}$ The Illinois Gestational Surrogacy Act defines compensation as the "payment of any valuable consideration for services in excess of reasonable medical and ancillary costs." 119 Compensating surrogates without exploiting poor women can be done by establishing requirements such as minimum wage earnings of the surrogate, placing a modest cap on the amount of compensation, or enacting other reasonable stipulations. ${ }^{120}$ More often than not, however, states do not allow for compensation beyond expenses for gestational surrogates to be a part of the gestational surrogacy agreement. ${ }^{121}$

Although there are public policy concerns regarding gestational surrogacy agreements, allowing those who enter into these arrangements to experience the joy of parenthood by guaranteeing the enforcement of their contracts should outweigh these seemingly archaic policy concerns. A validation of surrogacy agreements by a court would "have the effect of vesting the parental rights with the intending parents even before the baby is conceived ... [this] could eliminate some of [the state's] statutory problems."122

117 Id.

118750 ILL. CoMP. STAT. 47/25(a)(4) (2012); see also Ford, supra note 6 , at 88 (stating that Illinois and Utah, as of 2008, allowed for compensation of gestational surrogates).

119750 ILL. COMP. STAT. 47/10 (2012).

120 Tuininga, supra note 107, at 195 (States can pass legislation "that surrogates must possess financial means above a certain threshold in order for courts to enforce the contract. . . . [L]egislatures could criminalize arrangements with surrogates possessing resource limits below a designated level. . . . Virginia and New Hampshire already require pre-commencement court approval of surrogacy contracts." This pre-approval would help to ensure that a surrogate's financial records meet the requisite levels.).

121 Surrogacy Laws by State, THE SELECT SuRRoGATE, http://www. selectsurrogate.com/surrogacy-laws-by-state.html (last visited Aug. 3, 2012).

122 Alexander, supra note 105 , at 425-26 (Statutory problems would be eliminated because the "parental rights are technically never surrendered. The surrogate cannot be said to be relinquishing parental 


\section{B. Florida's Recognition and Strict Regulation of Gestational Surrogacy}

The State of Florida has passed legislation honoring gestational surrogacy agreements and regulating the conditions in which they may take place. ${ }^{123}$ While honoring these agreements, Florida also places many restrictions and requirements on the conditions of the gestational surrogacy agreements, making it difficult for many intended parents in Florida to comply with the statute. ${ }^{124}$ In doing so, the Florida Legislature has provided certain 'safe-guards' against some of the major public policy concerns with gestational surrogacy. ${ }^{125}$ The Florida statute states, "[p]rior to engaging in gestational surrogacy, a binding and enforceable gestational surrogacy contract shall be made between the commissioning couple and the gestational surrogate." 126 Additionally, the surrogate and intended parents must be at least eighteen years old. ${ }^{127}$ Couples may only commission a gestational surrogacy arrangement if the mother is unable to carry the child herself. ${ }^{128}$ Florida also

rights in return for consideration ('baby-selling') because she never gains parental rights during the process. Furthermore, the rights of the surrogate are protected by the stringent requirement that the contract be entered into voluntarily.").

123 See FLA. STAT. § 742.15 (2012).

124 See generally id. (The statute states, among other requirements, that: the intended mother must not be physically able to carry the child herself, the surrogate will make all medical decisions regarding pregnancy management, the surrogate cannot be compensated beyond pregnancy related expenses, and the surrogate must agree to assume parental rights of the child if "neither member of the commissioning couple is the genetic parent of the child.").

125 See id.

126 Id.

127 Id.

128 Id. (Florida law reserves the option for gestational surrogacy to mothers "who cannot physically gestate a pregnancy to term; [or situations in which] the gestation will cause a risk to the physical health of the commissioning mother; or the gestation will cause a risk to the health of the fetus."). 
requires that the commissioning parents be married. ${ }^{129}$

Florida requires a "determination of parentage" within three days of birth. ${ }^{130}$ However, Florida also requires that one of the intended parents be biologically related to the child in order to assert parenthood after the birth of the child. ${ }^{131}$ This requirement prohibits intended parents who are both infertile from participating in gestational surrogacy. Additionally, the birth mother's name is initially placed on the birth certificate until the court clerk prepares a certified statement to issue a new birth certificate within thirty days of the child's birth. ${ }^{132}$ Not until then is the biological/intended mother's name listed on the child's birth certificate. ${ }^{133}$ While this process allows intended parents to feel secure in the outcome of their gestational surrogacy agreement, it still puts many stipulations on both the surrogate and intended parents. ${ }^{134}$ These limitations appear to prohibit single individuals, unmarried couples, and homosexuals from participating in gestational surrogacy. Additionally, intended parents must still wait until after the child is born to establish parentage of the child and have their names placed on the child's birth certificate. ${ }^{135}$ This delay in establishment of parentage may prevent intended parents from taking their child(ren) home from the hospital after birth and making initial medical decisions regarding the child's health. ${ }^{136}$

\section{Illinois's Welcoming Gestational Surrogacy Laws}

Illinois passed the Gestational Surrogacy Act in 2004, providing intended parents with the security of knowing that a child conceived via IVF and gestated by a surrogate

129 See Id. (limiting the option of gestational surrogacy only for heterosexual couples).

130 FLA. STAT. § 742.16 (2012).

131 Id.

132 Id.

133 See id.

134 See $\S 742.15$.

$135 \S 742.16$.

136 Ford, supra note 6 , at 88. 
will automatically become their legal child at birth. ${ }^{137}$ Intended parents are given security in their future status as legal parents, knowing they will have sole custody of the child immediately after the child is born. ${ }^{138}$ Parentage can even be established prior to the birth of the child if both the intended parents and the gestational surrogate are represented by separate legal counsel and agree regarding the satisfaction of contract requirements."139 If the gestational surrogacy agreement is not valid for some reason, the court "shall deter-mine parentage based on evidence of the parties' intent." 140 This provides additional security for the intended parents in the event that their agreement with the gestational surrogate is not recognized.

"Illinois has some of the most comprehensive laws addressing gestational surrogacy in the country and should be adopted as a model by other states wishing to enact legislation allowing gestational surrogacy."141 Although Illinois has many requirements, these procedures help to make the gestational surrogacy arrangement secure and predictable for all involved parties. Illinois requires that the gestational surrogacy agreement be in writing and entered into prior to IVF. ${ }^{142}$ Additionally, the gestational surrogate must be at least twenty-one years old, must have previously given birth to at least one child, and must have completed medical and mental health evaluations. ${ }^{143}$ "[E] ach of the gestational surrogate and the intended parent or parents shall have been represented by separate counsel in all matters concerning the gestational surrogacy and the gestational surrogacy con-tract." 144 The surrogate must also have health insurance; however, the intended parents are

137 Scott, supra note 88, at 109 (The Gestational Surrogacy Act lists numerous requirements to make the arrangement enforceable. Notably, it "passed unanimously in both houses of the legislature.").

138750 ILl. COMP. STAT. 47/15 (2012); 750 ILL. COMP. STAT. 47/10 (2012).

139750 ILL. COMP. STAT. 47/35 (2012).

140750 ILL. COMP. STAT. 47/25(e) (2012).

141 Ford, supra note 6, at 101.

142750 ILL. COMP. STAT. 47/25 (2012).

143750 ILL. COMP. STAT. 47/20(a) (2012).

144750 ILL. COMP. STAT. 47/25(b)(3) (2012). 
permitted to pay for the health coverage during the pregnancy and up to eight weeks after birth. ${ }^{145}$ Illinois's statute allows for fair compensation to the gestational surrogate. ${ }^{146}$ If the agreement allows for compensation of the surrogate, "the compensation shall have been placed in escrow with an independent escrow agent prior to the gestational surrogate's commencement of any medical procedure."147 It should be noted, however, that Illinois's statute also states that "there shall be no specific performance remedy available for a breach by the gestational surrogate of a gestational surrogacy contract term that requires her to be impregnated." 148 This requirement prevents the intended parents from forcing a surrogate to be impregnated.

As an additional safeguard for the parties, Illinois courts shall presume enforceability of gestational surrogacy agreements. ${ }^{149}$ Illinois law also states that there are particular provisions that must be included in the gestational surrogacy agreements: the written consent of the surrogate, the consent of her spouse (if married), the right to choose her own physician after consulting with commissioning parents, and the consent of the intended parent(s) to accept custody and "assume sole responsibility" immediately following the birth of the child.150 Though these requirements seem stringent, the end result is that the intended parents' names can be on the child's birth certificate without special court authorization as long as a "voluntary acknowledgement of parentage" exists in accordance with the qualifications set forth by the Illinois Legislature. ${ }^{151}$

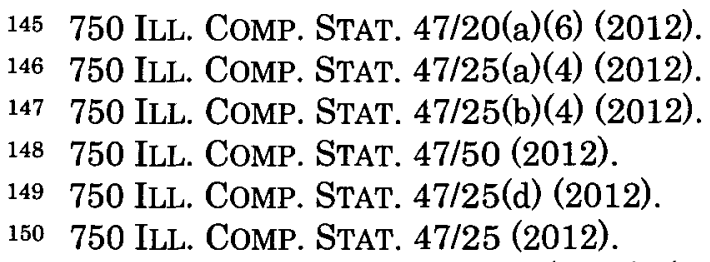

151750 ILL. COMP. STAT. 45/6 (2012) (In order to establish the intended parent-child relationship, the gestational surrogate must certify that she (and her husband, if she has one) is/are not biologically related to the child, the intended mother must certify that she or an egg donor are the biological mother of the child, the intended father must 
In addition to the safeguards provided to the parties, hospitals and physicians also face decreased liability under Illinois's gestational surrogacy laws. This is due to the reduced risk of later facing a lawsuit by either the intended parents or surrogate based on the results of the hospital's decisions in handling the birth certificate, parental rights, and/ or release of the child. Illinois's system also decreases confusion by having a standard procedure in which gestational surrogacy agreements are acknowledged and handled by hospitals. ${ }^{152}$ Hospitals know the requirements of the Gestational Surrogacy Act and are easily able to determine if the required provisions have been met or not. ${ }^{153}$ Ultimately, increased patient satisfaction by all parties is achievable due to the ability to alleviate the stress and anxiety that often come with the uncertainties of gestational surrogacy and the rights of the intended parents as the child's legal parents.

\section{BENEFITS OF ADOPTING ILLINOIS-STYLE LEGISLATION}

\section{A. Intended Parents Would Have Security in the Outcomes of their Arrangements}

Illinois, in having "some of the most comprehensive laws addressing gestational surrogacy in the country," is often used as a model for other states desiring to implement similar gestational surrogacy regulations. ${ }^{154}$ One of the

certify that he or a sperm donor are the biological father of the child, a physician must certify that the child is biologically related to at least one of the intended parents, the parties' attorneys must certify that they have entered into a gestational surrogacy agreement, and all of these certifications must be witnessed by two adults that are not party to any aspect of the agreement.).

152750 ILL. COMP. STAT. 47/15 (As long as the surrogate and intended parents "satisfy the eligibility requirements set forth in" 750 Illinois Compiled Statutes 47/20(a)-(b), and "pursuant to a gestational surrogacy contract meeting the requirements set forth in" 750 Illinois Compiled Statutes $47 / 25$, the intended mother and/or father will be the child's legal parents "immediately upon the birth of the child.".

153 See id.

154 Ford, supra note 6, at 101. 
obvious benefits of adopting an Illinois-style gestational surrogacy policy in Indiana is the decreased worry that parties would face regarding the court's interpretation of their intentions.

Very few states have addressed gestational surrogacy either through enacted statutes or case law. This often leaves parties to a gestational surrogacy agreement in uncharted territory, which could put them in a situation with unintended consequences ... Therefore, each state's legislature should enact gestational surrogacy statutes which provide clear guidelines for intended parents and surrogates. ${ }^{155}$

Furthermore, it would be possible for Indiana to allow gestational surrogacy while still prohibiting traditional surrogacy arrangements. ${ }^{156}$

If the legislature regulates gestational surrogacy agreements, Indiana would be able to provide security to intended parents who have invested significant amounts of money towards their last chance at raising a genetic child. With the average cost of IVF totaling around $\$ 14,500$ per round, in addition to costs paid to the surrogate and unpredictable legal fees, the cost for a couple to have a genetic child via gestational surrogacy can easily range between $\$ 25,000$ and $\$ 75,000.157$ In addition to the devastating result of losing a child through a gestational surrogacy dispute, intended parents may also lose significant amounts of money. This tumultuous scenario in a state that does not honor gestational surrogacy agreements has the potential to create an avenue for individuals to exploit the desires of intended parents and extort money from them while posing as a gestational

155 Id. at 86.

156 Brittnay M. McMahon, The Science Behind Surrogacy: Why New York Should Rethink its Surrogacy Contracts Laws, 21 ALB. L. J. SCI. \& TECH. 359, 372 (2011).

157 Ford, supra note 6, at 85. 
surrogate. ${ }^{158}$ The acknowledgement and regulation of gestational surrogacy agreements in Indiana would eliminate these potential scenarios by legally binding both parties to the agreement. Legal fees for the intended parents would be decreased because attorneys would know exactly how to create a binding agreement; thus, fewer legal expenses would occur by not having to attempt to navigate the unpredictable gestational surrogacy system in Indiana. ${ }^{159}$ Similarly, legal fees of providers would likely decrease because of the certainty regarding the proper custody of the child. "Unchartered, uncertain legal territory would not need to be forged each time a gestational surrogacy controversy or case arises; thus, legal expenses for intended parents would be minimized."160

\section{B. The Intent of the Parties would be a Determining Factor in Declaration of Parentage}

By acknowledging the intent required to enter into an agreement, the legislature would be showing that intent is a superior determination of parentage rather than other determining factors. This is a logical conclusion because "the procreation of the child resulted from 'a medical procedure [that] was initiated and consented to by intended

158 See generally FED. BUREAU OF InVESTIGATION, Surrogacy Scam Played on Emotions of Vulnerable Victims (Sept. 13, 2011), http://www.fbi.gov/news/stories/2011/september/surrogacy_091311/ surrogacy_091311 (This scam consisted of three women, two attorneys and a surrogacy facilitator, who defrauded families for over $\$ 100,000$ $\$ 150,000$ each. By lying to intended parents, surrogates, and the California court, these women sent surrogates to Eastern Europe to be impregnated by donor material. They then would wait until late in the pregnancy and contact potential intended parents to ask them to take over surrogacy arrangement that could not be fulfilled by the prior intended parents. In doing so, the scammers lied to the intended parents, surrogates, and the California Court. "The scam was uncovered when one of the surrogates, nearly seven months pregnant, was worried that parents hadn't been found for the baby she was carrying. She contacted a lawyer, who then contacted the FBI's San Diego office.").

159 Ford, supra note 6, at 97.

160 Id. 
parents."161 Conversely, using traditional factors, such as genetics or gestation, may have unintended consequences. For example, using biology as the sole determining factor of parenthood may discourage intended parents from using donor eggs or sperm for gestational surrogacy arrangements. ${ }^{162}$ Additionally, using gestation as the sole deter-mining factor would allow surrogates to decide to keep the child and would, as a result, promote the extortion of money from intended parents that are desperately seeking a child. ${ }^{163}$ Therefore, in addition to Illinois, other states have decided to focus the outcome of surrogacy cases on the intention of the parties instead of biology or gestation. ${ }^{164}$ Using the intention test helps to protect intended parents who used donor genetic material for the IVF process. By using donor material, there is no risk of the donor having a claim to parentage, only the surrogate. Donors have no claim to, or obligation of, parental rights as long as they enter into an agreement with the intended parents surrendering their rights. ${ }^{165}$ This relinquishment of donor rights and assumption of parental rights by the intended parents allows the intended parents to not have to worry about the legal ramifications of using a donor's genetic material to be implanted in the gestational surrogate. ${ }^{166}$

161 Bashur, supra note 26, at 170 (citing In re Marriage of Buzzanca, 72 Cal. Rptr. 2d 280, 293 (Cal. Ct. App. 1998).

162 Lewis, supra note 40 , at 395.

163 Id. at 398-99.

164 Bashur, supra note 26, at 168 (describing the outcome of Johnson v. Calvert, 5 Cal.4th 84 (Cal. 1993) by stating, "California was the first state to determine the outcome of surrogacy cases by focusing on intention, rather than on biology or gestation alone.").

165 Jeremy J. Richey, A Troublesome Good Idea: An Analysis of the Illinois Gestational Surrogacy Act, 30 S. ILL. U. L.J. 169, 177 (2005).

$166 I d$. ("The donor will have a duty to support a child 'only if he or she fails to enter into a legal agreement with the intended parent[s] . . . in which the intended parent[s] . . agree to assume all rights and responsibilities for any resulting child, and the gamete donor relinquishes his or her rights to any gametes, resulting embryos, or children." (quoting 750 ILL. COMP. STAT. 47/30 (2012))). 


\section{Pre-Birth Determinations of Parentage would be Predictable and Readily Available}

If gestational surrogacy agreements were recognized, parties would be able to request a determination of parentage prior to the birth of the child and, therefore, be assured of the outcome, provided that the agreement provisions had been honored by the parties. 167 Because gestational surrogacy is not a technology that will dissipate in popularity anytime soon, it is imperative that intended parents and gestational surrogates alike are able to have certainty regarding the outcomes of their arrangements. 168 In an Illinois-style system, the intended parents are the legal parents of the child upon birth, provided that all parties involved comply with the statutory provisions, and the child will be considered the legitimate child of the intended parents. ${ }^{169}$

\section{Surrogates will be Confident in the Outcomes of their Arrangements}

Gestational surrogacy statutes emulating Illinois's also protect the surrogate from being "stuck" with a child that she did not choose to have because the "intended parents will still have a duty to support the child financially even if they breach the contract." 170 Furthermore, challenges to rights of parentage can only be made within the first year of the child's life; after this point neither party will have to worry about any potential changes in their parenting status, providing all parties with additional security in the permanence of their agreement. ${ }^{171}$

167 Carla Spivack, Supplement, The Law of Surrogate Motherhood in the United States, 58 AM. J. CoMP. L. 97, 107 (2010) (describing the uncertainty of outcomes of determinations of parentage when the gestational surrogacy agreement is not acknowledged).

168 Id. at 114.

169 Richey, supra note 165 , at $173-74$.

170 Id. at 174.

171 Id. at 178 . 


\section{E. Hospitals and Physicians will be Confident in their Patient Care Decisions}

Under an Illinois-style system, the hospital and obstetrics physicians can simply place the intended parents' names on the birth certificate so long as all components of the Gestational Surrogacy Act have been met.172 This eliminates any potential liability on behalf of the physicians and hospital by having to make a judgment call regarding which parent(s) name can go on the birth certificate and who is allowed to take the child home.

Without this safety net of firm gestational surrogacy legislation, hospitals open themselves up to lawsuits from intended parents and/or gestational surrogates regarding the outcomes of their decisions regarding the child(ren). For example, in Pennsylvania, intended parents filed suit against the birthing hospital of their triplets, "stating that it conspired with the surrogate to prevent [the intended parents] from seeing [their] children at the hospital."173 In this case, the hospital released the triplets to return home with the surrogate, which began a custody battle between the surrogate and the intended parents. ${ }^{174}$ If Pennsylvania had enacted legislation regarding the validity of gestational surrogacy agreements, the hospital would have known exactly how to act and could have avoided this lawsuit entirely.

\section{Best Practice Suggestions for Physicians and HOSPITALS UNTIL INDIANA REGULATES AND RECOGNIZES GESTATIONAL SURROGACY AGREEMENTS}

Because Indiana's gestational surrogacy laws do not

172 Jackson, supra note 25, at 4.

173 Media Watch - Archive, The ORG. OF Parents Through SURROGACY, http://www.opts.com/mediawatcharchive.htm (last visited Aug. 17, 2012).

174 Andrew Vorzimer, Lawsuit Against Hospital over Surrogate Delivery of Triplets Allowed to Continue, THE SPIN Doctor (Sept. 24, 2009), http://www.eggdonor.com/blog/2009/09/24/lawsuit-againsthospital-over-surrogate-delivery-of-triplets-allowed-to-continue. 
provide procedures and regulations for medical providers to follow, it is difficult for hospitals and physicians to know what to do once the child(ren) of gestational surrogacy are born. If the parties have obtained a pre-birth parentage order prior to the birth of the baby, that order should be honored by the hospital in determining the names of the parents for the child's birth certificate. ${ }^{175}$ If the parties have not obtained a pre-birth parentage order, and there is time to do so before the birth of the baby, it would be prudent for the parties to seek a determination of parentage by the court; however, various jurisdictions within Indiana differ on the approval or denial of these orders. ${ }^{176}$

If a pre-birth parentage order cannot be obtained, the surrogate's name should be placed on the birth certificate and the intended mother will have to undergo an adoption hearing in order to become the legal mother of the child.177 While this outcome is not desirable for the surrogate or the intended parents, it is the best way for the hospital to prevent a lawsuit, as it is the only way to accurately follow Indiana's surrogacy laws. Additionally, the child(ren) should be sent home with the named parents on the birth certificate, whether that is the surrogate or the intended parents. Once the surrogate leaves the hospital, she may transfer the child over to the intended parents, if she so desires. If the surrogate desires to try to gain custody of the child, the hospital should remain removed from the situation and leave the parties to deal with the issues in court.

\section{CONCLUSION}

The most reliable way to ensure that the scope of the parties' rights in a gestational surrogacy arrangement are entirely realized is for the legislature to fully address these issues. ${ }^{178}$ It is difficult for hospitals and physicians to know how to respond to gestational surrogacy situations when

175 Jackson, supra note 25, at 3.

176 Id

177 Id.

178 Ohs, supra note 3 , at 341-42. 
different legal outcomes can occur each time. In order to alleviate confusion, stress, and even litigation from the gestational surrogacy process, Indiana should adopt an Illinois-style policy regarding its acknowledgement of gestational surrogacy arrangements. By regulating the circumstances in which gestational surrogacy arrangements can be legitimized, Indiana will have more control over the surrogacy realm than they do now by simply not acknowledging these agreements. Furthermore, in adopting a regulatory scheme, Indiana will prevent the anguish its residents face when their arrangements have an unanticipated ending; additionally, it will prevent the exploitation of particular populations that may be more susceptible to becoming gestational surrogates. Because Indiana citizens still enter into gestational surrogacy arrangements; therefore, it is advantageous for the state to regulate the industry rather than ignore it completely.

Until Indiana adopts a more specific, welcoming policy on gestational surrogacy, hospitals must be acutely aware of the ramifications of their actions should a party to the arrangement decide to change his/her mind. By honoring pre-birth determination orders, suggesting that parties obtain them before birth, and recognizing the surrogate as the legal mother until a court order states otherwise, hospitals and physicians can take the best possible steps to eliminate their risk in these scenarios. It is best for the hospital to remain as far removed from the legal issues surrounding gestational surrogacy as possible. By placing custody with whichever parent(s) names are listed on the birth certificate, and allowing the parties to work out the details amongst themselves, Indiana hospitals are reducing their legal risk. However, this outcome may not be desirable to the gestational surrogate and/or the intended parrents. Although it is a difficult decision for the hospital to make, particularly relating to controversial issues such as these, it is better for the hospital to base its decision on the law than on patient satisfaction. Until the legislature creates an adequate policy honoring gestational surrogacy agreements, physicians and hospitals should follow these recommendations. 